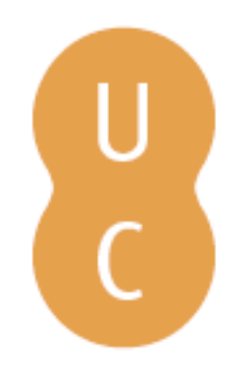

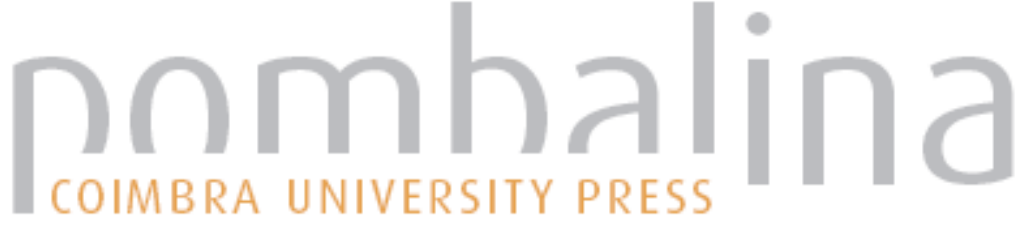

\section{A espiritualidade monástica num testemunho português do final da Idade Média: 0 Orto do Esposo}

\author{
Autor(es): $\quad$ Madureira, Margarida \\ Publicado por: Imprensa da Universidade de Coimbra \\ URL \\ persistente: URI:http://hdl.handle.net/10316.2/30843 \\ DOI: $\quad$ DOI:http://dx.doi.org/10.14195/978-989-26-0218-9_3 \\ Accessed : $\quad$ 26-Apr-2023 03:35:56
}

A navegação consulta e descarregamento dos títulos inseridos nas Bibliotecas Digitais UC Digitalis, UC Pombalina e UC Impactum, pressupõem a aceitação plena e sem reservas dos Termos e Condições de Uso destas Bibliotecas Digitais, disponíveis em https://digitalis.uc.pt/pt-pt/termos.

Conforme exposto nos referidos Termos e Condições de Uso, o descarregamento de títulos de acesso restrito requer uma licença válida de autorização devendo o utilizador aceder ao(s) documento(s) a partir de um endereço de IP da instituição detentora da supramencionada licença.

Ao utilizador é apenas permitido o descarregamento para uso pessoal, pelo que o emprego do(s) título(s) descarregado(s) para outro fim, designadamente comercial, carece de autorização do respetivo autor ou editor da obra.

Na medida em que todas as obras da UC Digitalis se encontram protegidas pelo Código do Direito de Autor e Direitos Conexos e demais legislação aplicável, toda a cópia, parcial ou total, deste documento, nos casos em que é legalmente admitida, deverá conter ou fazer-se acompanhar por este aviso.

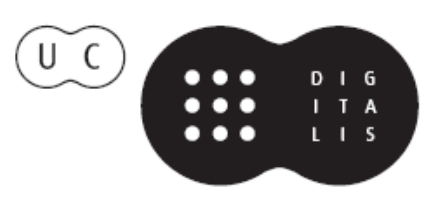


Marta Teixeira Anacleto e Elsa Branco

Coordenação

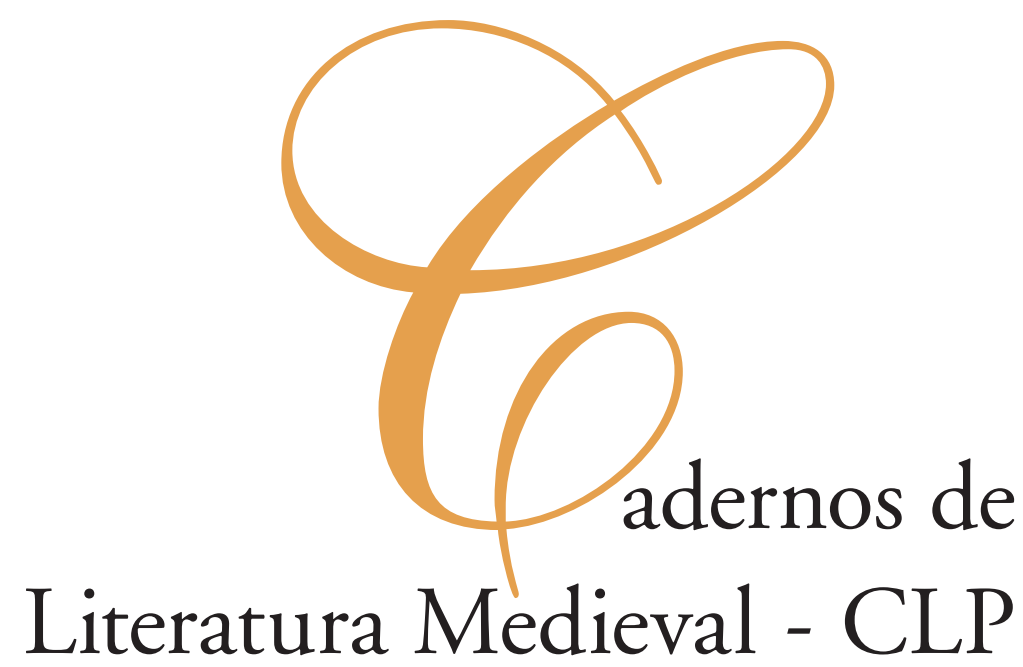

A Prosa Didáctica Medieval 


\section{Margarida Madureira}

Centro de Estudos Comparatistas

Universidade de Lisboa

\section{A ESPIRITUALIDADE MONÁSTICA NUM TESTEMUNHO PORTUGUÊS DO FINAL DA IDADE MÉDIA: O ORTO DO ESPOSO}

O ensinamento transmitido pelo Orto do Esposo organiza-se, como viu Mário Martins ${ }^{1}$, em três temas que fornecem ao texto a sua estrutura mais imediata, constituída por quatro livros: o primeiro incide sobre o nome de Jesus, a quem a obra é dedicada e que lhe dá o seu título; os livros seguintes referem-se à lectio divina, mas com uma diferença significativa entre ambos: o livro II, como o primeiro esclarecedor em relação ao título da obra, expõe num longo desenvolvimento a analogia entre o «orto» do Paraíso terrestre e as Sagradas Escrituras, horto deleitoso de Cristo, enquanto o livro III, de carácter mais pragmático, define um cânone de leituras pedagógicas e dá orientaçôes sobre o modo como as realizar por forma a delas tirar um proveito salutar $^{2}$; enfim, o livro IV, o mais extenso e corpo central da obra, explora largamente o tema do contemptus mundi, insistindo no exercício da ascese pelo qual o ser humano, libertando-se do peso da carne, retorna espiritualmente ao Paraíso perdido. Consequência do pecado original que afastou o homem das realidades celestiais e o

1 «Experiência religiosa e analogia sensorial», in Estudos de Cultura Medieval. Lisboa: Brotéria, 1969, pp. 65-77 (em particular, pp. 65-66).

2 Para uma análise dos preceitos aconselhados neste livro, veja-se o artigo de Ana Maria Machado, "O Orto do Esposo e as teorias interpretativas medievais», in J. M. Lucía Megías (ed.), Actas del VI Congreso interncional de la Asociación Hispânica de Literatura Medieval (Alcalá de Henares, 12-16 de septiembre de 1995). Alcalá de Henares: Universidad de Alcalá, vol. II (1997), pp. 925-935. Utilizo a edição realizada por Bertil Maler, Orto do Esposo. Texto inédito do fim do século XIV ou do comêço do século XV. Rio de Janeiro: Ministério da Educação e Cultura Instituto Nacional do Livro, 1956 (vol. I, Texto crítico; vol. II, Comentário), da qual indico, para facilitar a consulta, as páginas e as linhas. 
amarrou à terra, a ascese apresenta uma dupla vertente correlata, negativa e positiva: é liberto das preocupações materiais, no interior de si e através da meditação da Palavra de Deus, que o monge atinge, ainda que de forma efémera, imperfeita, aquele que é o objectivo de toda a sua vida, a visão do Céu $^{3}$. Compreende-se, neste contexto, a completa rejeição do mundo da experiência sensorial, que o monge alcobacense vê como raiz de todos os riscos e de todos os males, para a vida presente como para a vida futura. Consagra assim largos capítulos do livro IV a demonstrar os terríveis perigos que envolvem os cinco sentidos corporais, a que o ser humano deverá renunciar a favor dos sentidos espirituais ${ }^{4}$. O elogio da deficiência física (a cegueira, a surdez, etc.) explica-se, neste quadro, por se tratar de uma condição que favorece a contínua meditação interior, silenciosa e solitária, das coisas divinas, pois é entrando dentro de si que a alma descobre Deus.

Como explicar então a presença no Orto do Esposo de largos trechos que relevam da filosofia natural e da cosmologia? Como revela o seu autor no prólogo, ela resulta, antes de mais e de forma imediata, da solicitação a que a obra responde: o «liuro dos fectos [ant]ygos e das façanhas dos no[bres barôees] e das cousas marauilh[osas] do mũdo e das propiedades das [animal]ias» (pp. 1, 14-16) que a irmã, religiosa também ela num mosteiro cisterciense, lhe pediu e a que ele acedeu, não sem, contudo, reformular o projecto por forma a submeter a «sciencia segral» à «sciencia de Deus»; ou, por outras palavras, a filosofia natural à teologia. Esta constitui a segunda razão: humano ou divino, todo o conhecimento emana do «uerbo de Deus, que he Jh[esu Christo]» (pp. 3, 4-5). Todo o conhecimento, incluindo o saber das coisas profanas, é assim à partida positivo, desde que utilizado como um meio de conhecimento de Deus. Os escritos de S. Tomás representam um bom exemplo do que o monge cisterciense considera uma boa aplicação das ciências seculares:

O Doutor Sam Thomas entrou ẽno orto das sciencias seglaaes e tyrou dellas muytas flores dantre as spinhas e outrosy tomou dos liuros das Sanctas

\footnotetext{
${ }^{3}$ A obra de referência para toda a reflexão sobre a teologia monástica medieval é o belíssimo estudo de D. Jean Leclercq, L'Amour des lettres et le désir de Dieu. Initiation aux auteurs monastiques du Moyen Âge. Paris: Cerf, 1990 (3a ed. corr.). A ele se deve o principal impulso para a difusão desta noção. Expresso aqui a minha dívida para com este autor no que à compreensão do ideal que alimenta a vida monástica na Idade Média diz respeito.
}

${ }^{4}$ Cf. M. Martins, «Experiência religiosa», pp. 65-77. 
Scripturas e dos sanctos doutores muytas cousas proueytosas e de grande fruyto pera ssy e pera todolos fies de Jhesu Christo. (pp. 25, 30-34)

O autor do Orto do Esposo utiliza no seu tratado os feitos notáveis dos heróis e santos do passado e as numerosas descrições do mundo físico numa intenção em tudo idêntica à de S. Tomás: tirar "flores dantre as spinhas», ascendendo assim do conhecimento do mundo ao conhecimento espiritual.

Analisemos com um pouco mais de atenção o segundo tipo de exemplos. A principal fonte do monge alcobacense no que respeita às características biológicas das plantas e dos animais é, como mostrou B. Maler no volume II da sua edição, o De proprietatibus rerum de Bartolomeu Ânglico. Terminada sem dúvida na década de 40 do século XIII, em Magdeburg, esta é, como se sabe, a enciclopédia que maior sucesso conheceu no final da Idade Média, dela subsistindo mais de 300 manuscritos latinos e vários incunábulos, para além de numerosas reescritas e traduções, nas mais diversas línguas ${ }^{5}$. Resta-nos ainda hoje o exemplar desta enciclopédia existente à época na biblioteca do Mosteiro de Santa Maria de Alcobaça. Obra facilmente acessível ao autor do Orto do Esposo, o De proprietatibus rerum punha à sua disposição, numa perspectiva simultaneamente científica e vulgarizadora, todo o conhecimento contemporâneo no domínio da filosofia natural.

O recurso a uma enciclopédia científica num tratado que propugna um tão completo desprendimento do mundo é menos surpreendente do que se poderia pensar. A ciência não exclui, no século XIII - não exclui, talvez, bem mais tarde, nos séculos XVI-XVII - a dimensão religiosa e moral do saber. A enciclopédia de Bartolomeu Ânglico desenvolve um conhecimento estruturado sobre o mundo criado, ocupando-se do que o autor do Orto do Esposo classifica como «sciencias segraaes» ou «sciencias mũdanaes». Mas, como o monge cisterciense, o frade inglês não pensa que a explicação racional e completa dos fenómenos naturais seja incompatível com a ciência de Deus, a teologia ${ }^{6}$. Bem pelo contrário: não sendo a racionalidade da natureza mais

5 Para o estudo da concepção e recepção da enciclopédia do frade franciscano, incluindo o recenseamento e análise dos textos que dela derivam, consulte-se H. Meyer, Die Enzyklopädie des Bartholomäus Anglicus. Untersuchungen zur Rezeptionsgeschichte von De proprietatibus rerum. München: Wilhelm Fink Verlag, 2000.

${ }^{6}$ Para um debate sobre esta questão, veja-se a acesa polémica que opôs A. Cunningham e E. Grant, em particular após a publicação, em 1996, da monografia que o primeiro assinou 
do que um reflexo da própria racionalidade divina, o seu conhecimento constitui um meio de aceder ao conhecimento de Deus. Não é sem dúvida por acaso que as enciclopédias moralizadas destinadas à pregação derivam, sem excepção, quer desta obra de Bartolomeu Ânglico, quer da de Tomás de Cantimpré7.

Esta utilização é favorecida pelas notas marginais que acompanham a edição do $D e$ proprietatibus rerum na maior parte dos manuscritos latinos (incluindo no alc. 383).

com R. French, Before Science. The Invention of the Friars' Natural Philosophy. Aldershot: Scolar Press. Para a bibliografia desta controvérsia, cf. S. D. Snobelen, "To discourse of God: Isaac Newton's heterodox theology and his natural philosophy», in P. B. Wood (ed.), Science and Dissent in England, 1688-1945. Aldershot: Ashgate, 2004, pp. 39-65 (em particular, pp. 20-21, $\left.n^{\circ} 27\right)$. A oposição entre estes dois investigadores decorre da perspectiva, diacrónica ou sincrónica, que cada um adopta em relação ao estudo da ciência na Idade Média. Não se pode excluir a legitimidade de procurar as raízes do presente no passado, como faz E. Grant. Forçoso se torna porém admitir que esta visão hegeliana, teleológica, da história da ciência pode ser útil ao conhecimento do presente, mas, não acautelando a necessária reconstituição dos modelos do pensamento de cada momento sincrónico da história, em nada contribui para o conhecimento do passado. Pelo contrário, ela tende a obscurecer as estruturas próprias de cada época. Num mundo que desconhece a noção de «laicidade», a ideia de uma autonomia da ciência em relação à teologia não tem sentido, como creio, aliás, um outro estudo do próprio E. Grant, God and Reason in de Middle Ages (Cambridge: Cambridge University Press, 2001), deixa claro. A ciência medieval tem por objecto um mundo criado por Deus (já que não se concebe outra possibilidade) e este postulado de princípio, subjacente a toda e qualquer reflexão sobre o mundo físico, faz toda a diferença. A ideia de «libertar» a cosmologia ou a física natural de Deus pareceria a um clérigo medieval absurda, o que não significa que as realidades do mundo físico não possuam as suas regras próprias, passíveis de serem descritas por si. A questão da relação entre teologia e filosofia natural, menos simples do que os termos da polémica Cunningham-Grant podem fazer crer (como o próprio E. Grant se mostra consciente em God and Reason), é ainda pertinente nos séculos XVI-XVII: cf. a noção de «teologia secular» de Amos Funkenstein, Théologie et imagination scientifique: du Moyen Âge au XVIII siècle. Paris: PUF, 1995 (ed. orig.: 1986). Não queria deixar de acrescentar que, se no que respeita à ideia de que a filosofia natural, na Idade Média, descreve e explica um universo criado por Deus, e a sua relação com Deus - muito pertinente para Bartolomeu Ânglico - , as críticas de E. Grant às teses de A. Cunningham me parecem infundadas; pelo contrário, creio ser justa a acusação que o mesmo investigador faz ao carácter por vezes parcial da interpretação dos textos na monografia de French e Cunningham referida no início desta nota, analisados exclusivamente em função da tese que os seus autores se propōem demonstrar: leia-se, nomeadamente, "God, science, and natural philosophy in the late Middle Ages», in L. Nauta e A. Vanderjagt (eds.), Between Demonstration and Imagination. Essays in the History of Science and Philosophy Presented to John D. North. Leiden: Brill, 1999, pp. 243-267.

7 Cf. C. Meier, «Organisation of knowledge and encyclopaedic ordo: functions and purposes of a universal literary genre», in Pre-Modern Encyclopaedic Texts. Proceedings of the second COMERS Congress, Groningen, 1-4 July 1996. Leiden: Brill, 1997, p. 103-126 (em particular, p. 118-119); e L. Thorndike, "The Properties of Things of Nature Adapted to Sermons", Mediaevalia et Humanistica, vol. 12 (1958), pp. 78-83. 
De forma assaz surpreendente para quem vê nas enciclopédias do século XIII um processo de secularização das "ciências» naturais que se manifestaria na emancipação das descrições físicas em relação ao simbolismo tipológico a que se acham intrinsecamente ligadas nos bestiários e lapidários moralizados, diversos livros do $D e$ proprietatibus rerum contêm um largo número de notas à margem que expõem ao leitor os sentidos alegórico e moral das realidades descritas no corpo do texto. Este facto foi ignorado durante muito tempo. $\mathrm{Na}$ ausência de uma edição crítica desta obra, que apenas agora se acha em curso de publicação ${ }^{8}$, os investigadores recorreram à impressão de 1601 (ou à respectiva reprodução anastática de 19649 $)$. Ora, esta, para além de diversas lições defeituosas, elimina, como todas as outras edições impressas, as rubricas marginais ${ }^{10}$, muito ricas nos livros consagrados às aves e aos animais, a

${ }^{8}$ A edição do De proprietatibus rerum, assegurada pela editora belga Brepols, acha-se a cargo de uma equipa internacional coordenada por H. Meyer, B. Ribémont e B. van den Abelle. Saíram até ao momento dois volumes, ambos com data de 2007: o vol. I, que inclui o prólogo e os livros I a IV (B. van den Abeele, H. Meyer, M. W. Twomey, B. Roling e R. J. Long, eds.) e o vol. VI, contendo o livro XVII (I. Ventura, ed.). Esta edição prevê a publicação de todas as notas marginais. Incluirá ainda a tradução francesa realizada por Jean Corbechon para Carlos V e terminada em 1372.

${ }^{9}$ Cf. De genuinis rerum coelestium, terrestrium et inferarum proprietatibus. Liber de proprietatibus rerum. Frankfurt: W. Richterum, 1601; e para o fac-símile desta edição: Frankfurt: Minerva, 1964.

10 Os coordenadores da edição referida na nota 8 abordaram em vários artigos a questão das anotações marginais: cf. "Éditer l'encyclopédie de Barthélemy l'Anglais: vers une édition bilingue du De proprietatibus rerum». Cahiers de Recherches Médiévales. Vol. 6 (1999), pp. 7-18; de H. Meyer e B. van den Abelle, "État de l'édition du De proprietatibus rerum», in B. van den Abeele e H. Meyer (eds.), Bartholomaeus Anglicus, De proprietatibus rerum. Texte latin et réception vernaculaire/Lateinischer Text und volkssprachige Rezeption. Actes du colloque international/Akten des Internationalen Kolloquiums. Turnhout: Brepols, 2005, pp. 1-12; e, de B. Van den Abeele, a introdução geral ao volume I da edição, pp. 3-33. Dos livros editados até agora, apenas a segunda metade do livro IV (vol. I) e o livro XVII, referente às plantas (vol. VI), são acompanhados de notas, comentadas nas respectivas introduções de R. James Long (vol. I, pp. 198-199) e I. Ventura (vol. VI, pp. XXXIV-XXXVIII). As anotações que acompanham o livro XII, sobre as aves, foram publicadas, sem o texto que glosam, por B. van den Abeele, «Simbolismo sui margini. Le moralizzazioni del De Proprietatibus Rerum di Bartolomeu Anglico», in D. Faraci (ed.), Simbolismo animale e letteratura. Manziana: Vecchiarelli, 2003, pp. 159-183. Para um estudo recente da dívida do monge alcobacense em relação a esta enciclopédia, veja-se de A. Deyermond, "The Bestiary tradition in the Orto do Esposo», in M. E. Schaffer e A. Cortijo Ocaña (eds.), Medieval and Renaissance Spain and Portugal. Studies in honor of Arthur L-F. Askins. London: Tamesis, 2006, pp. 92-103, bem como duas comunicações apresentadas no VI colóquio sobre as Formas narrativas breves na Idade Média: A. P. Morais, «L'animal comme exemple dans l'Orto do Esposo: de l'exemplum à l'insertion exemplaire»; e M. Madureira, "Les oiseaux dans les exempla de l'Orto do Esposo", in B. Darbord e C. García de Lucas (eds.), Typologie des formes brèves au 
que principalmente recorre o autor do Orto do Esposo. A atribuição da autoria destas notas ao próprio Bartolomeu Ânglico é uma questão que divide os críticos contemporâneos. G. Dahan mostra-se convicto de que elas serão da responsabilidade do frade franciscano ${ }^{11}$. É bem possível que tenha razão. Qualquer que seja o caso, como mostram as investigaçôes de H. Meyer, elas estão longe de constituir um acidente na tradição manuscrita da obra: acham-se presentes desde os manuscritos mais antigos que nos chegaram, persistindo de forma sistemática ao longo dos séculos XIII e XIV.

Subjacente a esta hierarquização do saber, reconhece-se a imagem tópica do duplo livro de Deus - o liber scripturae e o liber naturae -, sobre cuja exacta similitude é construído o livro II do Orto do Esposo. Na entrada «Nature et vie spirituelle» que assina no Dictionnaire de spiritualité ascétique et mystique, o Padre Solignac insiste com particular ênfase na dimensão espiritual da ideia de natureza - «la nature comme chemin de contemplation, comme voie d'accès à une connaissance spirituelle de Dieu» ${ }^{12}$-, que informa os diversos tratados do tipo De rerum natura, entre os quais se inclui a enciclopédia de Bartolomeu Ânglico. Mais recentemente, R. French e A. Cunningham puseram em evidência a abordagem mística da natureza que orienta os tratados franciscanos de filosofia natural ${ }^{13}$. O estudo da natureza constitui assim uma etapa num percurso que visa a contemplação mística e o louvor de Deus, pela obra prodigiosa da Criação. Percebe-se, nesta perspectiva, que a significação espiritual e moral dos fenómenos naturais que as anotaçôes marginais, qualquer que seja o seu autor, expóem ao leitor, ao invés de constituir um plano segundo, acrescentado por quem pretendia facilitar a utilização da obra na pregação, é, pelo contrário, consubstancial à teologia espiritual que, sem dúvida, motivou a redacção do De proprietatibus rerum. $\mathrm{Na}$ verdade, estas notas são o único momento do texto em que se cumpre o desígnio expresso pelo seu autor no prólogo: ajudar à compreensão dos enigmas da Bíblia, que o Espírito Santo inscreveu sob o véu de símbolos e figuras nas propriedades das coisas

Moyen Âge (domaine roman). Colloque international tenu les 14 et 15 mars 2008, Université Paris $X$-Nanterre et Fondation Calouste Gulbenkian-Paris. Paris: Presses de l'Université de Paris X-Nanterre (no prelo).

11 Lire la Bible au Moyen Âge. Essais d'herméneutique médiévale. Genève: Droz, 2009, pp. 123-124.

12 Dictionnaire de spiritualité ascétique et mystique. Doctrine et histoire. Paris: Beauchesne. Vol. XI (1982), col. 44-55; cf., para a citação, col. 45.

13 Before Science, passim. 
naturais e $\operatorname{artificiais~}^{14}$. Note-se que são os livros que já dizem directamente respeito às realidades espirituais, cujo estudo pertence (também) à teologia (Deus, os anjos, a alma, etc.), que são desprovidos de rubricas marginais.

Como nos textos de Roberto Grosseteste e Rogério Bacon analisados por R. French e A. Cunningham, a referência para este movimento de ascensão contemplativa é o Pseudo-Dionísio Areopagita, apoiado no versículo 1, 20 da Epistola aos Romanos de S. Paulo: «Invisibilia enim Dei per ea que facta sunt intellecta cognoscuntur». Na verdade, o Pseudo-Dionísio não faz parte do corpus de leituras monásticas. O anónimo autor do Orto do Esposo narra porém um exemplum a seu respeito (III, 11), retirado sem dúvida da biografia que dele oferece a Legenda Aurea onde, de acordo com a tradição, o filósofo grego é identificado com o santo mártir de Paris. Sábio pagão de Atenas, Dionísio/Dinis ascende, através do estudo da filosofia, ao conhecimento do Deus verdadeiro. A observação dos fenómenos do mundo físico, e em particular do eclipse que ocorreu durante três horas no momento da morte de Cristo, inexplicável pelas regras que regem a natureza, levam-no a penetrar a luz espiritual que nesse momento brilha intensa sob as trevas provocadas pelo «scuricimẽto do sol»: «Esta nocte noua, de que nos marauilhamos, sinifica que hũa luz uerdadeyra ha de vĩin ao mũdo» (pp. 68, 22-23). A citação que Bartolomeu Ânglico transcreve do Pseudo-Dionísio recorre, também ela, à luz como imagem da revelação dos mistérios de Deus inscritos no mundo criado:

\begin{abstract}
Non est nobis aliter possibile lucere diuinum radium, nisi varietate sacrorum velaminum anagogice circumvelatum. Quoniam neque possibile est nostro animo ad immaterialem illam celestium hierarchiarum ascendere contemplationem, nisi ea, que secundum ipsum est, materiali manuductione utatur visibiles formas invisibilis pulcritudinis imagines arbitrans, etc. (I, pp. 51, 11-18).
\end{abstract}

Ora, como afirmam ainda R. French e A. Cunningham, para os franciscanos, estudar a luz é estudar Deus. Subjacente ao exemplum de Dinis/Dionísio acha-se o mesmo postulado da dimensão teológica do mundo.

14 «(...) ad intelligenda enigmata Scripturarum, que sub symbolis et figuris proprietatum rerum naturalium et artificialium a Spiritu sSancto sunt tradite et velate (...)» (I, pp. 51, 7-10). 
O mesmo capítulo contém outros exempla que ilustram o modo como o estudo da filosofia natural pode abrir caminho à fé teológica: caso de um «doutor», convertido através da leitura do astrólogo Albumasar (pp. 67-68). Todos eles são convergentes com a narrativa sobre Tomás de Aquino: o importante é retirar da inquirição do mundo natural o conhecimento da revelação de Deus. A subalternização do mundo material domina, como seria expectável, o pensamento do Orto do Esposo. Não é assim demais insistir na pequena abertura à experiência directa da realidade sensível que, no exemplum de S. Dinis, substitui o saber livresco como meio de aceder aos invisibilia Dei.

Desconhecendo o Pseudo-Areopagita, o monge alcobacense não teve, no entanto, qualquer dificuldade em interpretar o prólogo do De proprietatibus rerum à luz do neoplatonismo cristão de Agostinho, autoridade de referência da teologia monástica, para quem remete no final do capítulo:

E asy parece que a sciencia da filosafia ajuda algũas uezes algũũs pera se tornarem aa uerdade, e nô he marauilha, ca de Jhesu Christo saae[m] e nacem todalas sabedorias, nõ tam solamẽte as sciencias sanctas e diuynaaes mas ajnda as sciencias dos filosafos gentiis, ca elle he fonte de todalas sciencias, segũdo diz Sancto Agostinho (...). (pp. 69, 16-21).

O Orto do Esposo não recorre ao De proprietatibus rerum apenas como um repositório particularmente rico de descrições detalhadas dos animais e das plantas, incluindo pistas para a sua glosa moral. Retira desta obra também todo o primeiro capítulo do livro II, no qual descreve o Paraíso terrestre e o lugar que nele ocupava o homem, eleito para o habitar, bem como dois trechos muito significativos do livro IV: no início do capítulo 3, a explicação sobre a finalidade dos animais, destinados ao proveito do homem; e, no começo do capítulo 10, uma cosmografia cujo dualismo deriva no topos, frequente no tratado alcobacense, do desterro que o ser humano vive neste mundo. $\mathrm{Na}$ verdade, os primeiros capítulos do livro IV que se seguem aos dois prólogos assentam na combinação destas e doutras descrições físicas das realidades do mundo natural, extraídas do De proprietatibus rerum, com passos de um dos tratados mais representativos da corrente do contemptus mundi, o De miseria humanae conditionis de Lotário de Segni, futuro papa Inocente III ${ }^{15}$, sem que o monge alcobacense pareça identificar qualquer contradição entre estes dois textos.

15 Cf. Lotharii cardinalis (Innocentii III), De Miseria humane conditionis. Lugano: Thesaurus Mundi, 1955; ou Patrologia Latina. Vol. 217, col. 701-746. É sobre a miséria da condição 
Os excertos traduzidos nos capítulos II, 1 e IV, 10 correspondem, na obra de Bartolomeu Ânglico, a representaçôes de natureza geográfica e cosmológica, respectivamente. A exposição sobre o Paraíso terrestre - cuja existência geográfica real a Idade Média não punha em dúvida - surge aí no contexto de uma longa exposição sobre várias regióes da terra, que ocupa todo o livro XV. Quanto à cosmografia de IV, 10, ela adapta o capítulo inicial do livro VIII do De proprietatibus rerum, o qual trata «do céu, do mundo e dos planetas». Qual a função e a significação que os trechos que acabo de referir adquirem no texto alcobacense? Pese embora a dimensão ética e cristã que a cosmologia descrita na enciclopédia do frade inglês possui, basta a simples transposição do contexto científico original para o novo contexto de moral ascética do Orto do Esposo para que o seu sentido se altere. A selecção operada pelo monge cisterciense na obra de Bartolomeu Ânglico e a articulação que realiza entre as descrições do mundo físico que dela retira e largos passos, não apenas do De miseria humanae conditionis, mas também de outras autoridades doutrinárias (Hugo de S. Victor, Isidoro de Sevilha, Santo Agostinho, Gregório Magno, etc), para não falar das numerosas citações bíblicas, nos capítulos iniciais do livro IV, dão conta da intenção de proceder à profunda integração teológica dos elementos de filosofia natural, pois, como diz Boécio, "a nossa fe he tirada das cousas mais dedentro da filosafia» (pp. 67, 30-31).

Sublinhe-se, antes de mais, que a inserção e adaptação a este novo contexto não retira aos trechos que o monge alcobacense utiliza do De proprietatibus rerum o seu carácter de descrição objectiva do mundo criado. Na expressão «sciencias mũdanaes» (pp. 67, 6), o adjectivo deve ser antes de mais compreendido na sua acepção cosmológica: o mundo como universo, obra da criação divina ${ }^{16}$. Podemos considerar sinónimas as

humana que o futuro papa se propõe escrever, como afirma no prólogo, pelo que este título é mais adequado do que o de Liber de contemptu mundi. Posterior, este último resulta de uma recepção que integra, com justeza, o tratado nesta corrente. Redigido pelo cardeal Lotário em 1196, a obra conheceu uma difusão imensa. A prová-lo, estão os mais de 700 manuscritos que dele subsistem. Do século XVII, conhecem-se ainda 50 reimpressões. Sobre a doutrina do contemptus mundi nesta obra, veja-se R. Bultot, «Mépris du monde, misère et dignité de l'homme dans la pensée d'Innocent III", Cahiers de civilisation médiévale, vol. IV (1961), pp. 441-456. Para as fontes do Orto do Esposo, cf., para além das notas incluídas no vol. II da edição de B. Maler, já antes mencionado, o vol. III, do mesmo autor, publicado mais tardiamente: Orto do Esposo, vol. III. Correcçôes dos vols. I e II, estudo das fontes e do estado da língua, glossário, lista dos livros citados e indice geral. Stockholm: Almqvist \& Wiksell, 1964, pp. 18-22.

16 Para os diversos sentidos de "mundo», veja-se o artigo de P. Daubercies a ele dedicado na enciclopédia Catholicisme: hier, aujourd'hui, demain. Paris: Letouzey et Ané. Vol. IX (1982), col. 547-563. 
expressões «sciencias naturaaes» (pp. 67, 9) e «sciencia da filosafia» (pp. 69, 16), utilizadas umas linhas adiante. O mundo interessa o autor do Orto do Esposo na medida em que é nele que tem lugar a história salvífica do homem. Trata-se, pois, de conferir à sua vida terrestre, como à vida de cada ser humano, uma dimensão cosmológica.

De forma mais imediata, como mostrou R. Bultot, o desprezo do mundo encontra importantes argumentos no dualismo cosmológico herdado da Antiguidade, que Bartolomeu Ânglico retoma e de que faz eco o nosso autor, entre outros, no longo passo que traduz no capítulo IV, $10^{17}$. Esta representação cosmográfica assenta em dois princípios fundamentais: o geocentrismo e a teoria dos quatro elementos, cuja pureza é inversamente proporcional à sua materialidade. É na medida em que a terra constitui o mais pesado e o mais vil dos elementos que o globo terrestre ocupa o centro do universo. Ora, ao contrário dos peixes e das aves, feitos da água, o homem foi, do mesmo modo que os animais terrestres, elaborado a partir daquele elemento espesso, opaco e grosseiro. A teoria dos quatro elementos explica assim a inferioridade ontológica do homem em relação a outros animais no que respeita ao seu corpo ${ }^{18}$. Não decorre daqui à partida qualquer juízo ético ou moral, mas apenas um juízo de valor sobre a condição terrestre do homem, que precede aquele ${ }^{19}$.

O que faz então da carne e do mundo, que em si não são maus, os principais aliados do diabo e a condição primeira do pecado? No Paraíso original, a carne achava-se submetida ao espírito. Ora, é a alma, concebida à imagem e semelhança de Deus, que faz a superioridade do homem face aos outros animais: "Tal alma criou Deus ao homẽ, que ella fosse milhor per razõ e per jntelligencia que todalas animalias da terra e do mar e do aar, que nõ am tal mẽte como a do homẽ» (pp. 82, 26-29), afirma o autor do Orto do Esposo por intermédio de uma citação de S. Agostinho. A condição desprezível do «homẽ animal» (pp. 48, 14) explica-se pela sua sujeição histórica ao

17 "Cosmologie et contemptus mundi», in "Sapientiae doctrina». Mélanges de théologie et de littérature médiévales offerts à Dom Hildebrand Bascour O.S. B. Recherches de théologie ancienne et médiévale. Numéro spécial (1980), pp. 1-23 (passim); para Bartolomeu Ânglico, cf. p. 15.

${ }^{18}$ Numerosos passos do Orto do Esposo evidenciam esta situação. Cito, a título de exemplo, o passo inicial de IV, 2, que o autor alcobacense traduz do De miseria humanae conditionis: "Consiirando o homẽ todas as cousas, deue-sse teer por mais uil que ellas, quanto pertẽẽce a sua carne. Porque o Senhor Deus formou o homẽ da terra, s. do limo della, que he mais uil que todolos elemẽtos, e elle fez as planetas e as strellas do elemẽto do fogo e fez os uẽtos do aar e fez os pexes e as aues da agua e fez os homẽẽs e as bestas da terra» (pp. 94, 7-12).

19 Cf. R. Bultot, «Cosmologie et contemptus mundi», p. 4. 
pecado, que rebaixou o ser humano ao nível dos animais ctonianos ${ }^{20}$. Perdida a graça divina, o homem fica entregue aos desejos da carne, corpo de pecado. A harmonia entre o corpo e o espírito converteu-se numa violenta oposição, a ponto que o primeiro se converteu no cárcere da alma e a vida na terra num exílio doloroso. Aspirando à visão do Céu, o espírito é permanentemente cerceado nos seus intentos pela carne: "(...) ho homẽ he diuiso e partido ẽ si meesmo, ẽ guisa que a uôtade da sensualidade da carne he contra a uõtade da alma (...)» (pp. 82, 15-16). A ascese impóe-se assim como forma de arrancar o ser humano ao que o desnatura. O Orto do Esposo explora longamente este tema no segundo prólogo do livro que tenho vindo a analisar, bem como nos seus capítulos iniciais.

Não cabe aqui analisar a densa trama doutrinal que, sobretudo através da combinação de material discursivo em segunda-mão, o monge cisterciense desenvolve nos dois prólogos e nos capítulos iniciais do livro IV. Retenho, para o que me interessa, que em consequência do pecado original, o ser humano perdeu a inteligência espiritual que lhe permitia interpretar a mensagem que Deus lhe transmite através da natureza: expulsa do Paraíso, a alma "perdeo a luz das cousas que nó podem seer uistas, toda se espage[o] ẽno amor das cousas terreaes, retornou-se de ueer as cousas perdurauis e foy feyta muy ffea» (pp. 84, 8-11). Descurou, assim, os «bẽẽs uerdadeiros, que som os celestriaaes», para se fixar nessa «sõôbra (...) ou jmagem que parece emno espelho», que o diabo roubou «das uirtudes e das boas obras» com o único propósito de a conduzir à morte eterna, vulnerável que se acha já pelo primeiro pecado (cf. pp. 95, 11. 24-29).

Obra da criação divina, o mundo encerra uma mensagem susceptível de conduzir o homem para Deus: no livro II, a descrição da natureza maravilhosa do Paraíso, com a qual "he conparada e semelhãte a Sancta Escriptura», não nos diz outra coisa. Ele é, no entanto, simultaneamente, após a queda, lugar de pecado, de transgressão dos mandamentos de Deus e de morte e, nesta perspectiva, é necessariamente encarado como uma realidade negativa, susceptível de levar o homem à perdição. Note-se, a este respeito, uma dupla abordagem do Paraíso, respectivamente no livro II e no início do livro IV. Cosmografia (II, 1) e alegoria da verdade divina (II, 2-14), o primeiro corresponde à descrição eufórica de um espaço em que o tempo não se faz

20 «Côparado he aas bestas e fecto semelhante a ellas» (pp. 83, 32-33). 
sentir ${ }^{21}$, no Paraíso terrestre original, concebido para o homem «feyto per mãão de Deus» e à sua imagem e do qual se acha excluída a «animalia bruta» (pp. 15, 23-25), isto é, os animais terrestres, feitos como o homem do elemento mais vil, mas destituídos de alma. A bondade da natureza manifesta-se no mundo anterior ao pecado original, quando o homem a conhecia e através dela acedia ao conhecimento de Deus. Veja-se a menção à nomeação dos animais no Paraíso, através de uma citação de Hugo de S. Victor, a qual, na perspectiva de uma motivação da linguagem original em relação às coisas, só pode significar o conhecimento dessa realidade - e da própria Realidade, como mostra a alegoria espiritual da natureza do Paraíso original do livro II. É ao conhecimento desta Realidade que se acha destinado o homem; e, por isso, ao contrário, dos outros animais, que "ham suas faces ẽclinadas e abayxadas contra terra", o "homẽ ha a sua face leuãtada pera o ceeo pera teer mentes e olhar o seu Creador» (pp. 96, 33-35).

O monge alcobacense não tem dificuldade em articular esta perspectiva extremamente sombria sobre o mundo e o homem, claramente devedora em relação às epístolas de S. Paulo, com a cosmografia que transcreve do De proprietatibus rerum. A mesma realidade do mundo criado, longamente exaltada em virtude da natureza fecunda e exuberante com que Deus, no seu poder e na sua bondade, a beneficiou ${ }^{22}$, é simultaneamente, sem que nisso o Bartolomeu Ânglico veja qualquer contradição, depreciada e condenada. Como referi acima, existe uma razão ontológica para esta desvalorização. A negatividade do mundo é, no entanto, deste ponto de vista, apenas relativa. Ela explica-se à luz do neoplatonismo cristão que o frade franciscano combina com elementos de proveniência aristotélica: as qualidades positivas do mundo natural não são mais do que o reflexo que nele têm as realidades superiores ${ }^{23}$. A segunda razão é histórica: o pecado fez do mundo

21 Sintoma desta atemporalidade, a preceder a intemporalidade do eterno, é a ausência de morte: «(...) onde diz Sancto Agostinho ẽno liuro da Cidade de Deus que, sse o homẽ fora obediente a Deus e guardara o seu precepto, passara do parayso terreal pera a companha dos angeos sem morte nehũa e uiuera pera senpre uida bemauẽturada nõ mortal» (pp. 83, 19-23).

22 Cito a partir da selecção e tradução que deste louvor da Criação dá o Orto do Esposo: «(...) Outrossy, a parte do mũdo mais baixa quanto parece que perdeo da claridade e da fremusura, tăto cobrou ẽ graça e ẽ uirtude de auôdança, ca nô he meos marauilhosa a uirtuosa auôdança da terra ẽ lançar de sy heruas e aruores e flores e fruytos e muytas animalias de desuayradas maneyras e muytos metaaes e pedras preciosas ca a claridade do ceeo cô suas strelas» (pp. 118, 26-31).

23 Santo Agostinho, apud Bartolomeu Ânglico, na tradução do monge alcobacense: «(...) ẽ tanto he per todo mais fremoso o mũdo ẽ canto a parte do mũdo mais fea e mais bayxa he 
(...) carcer dos spiritus e das almas e esterramẽto muy duro e loguar de mezquindades e de penas, ca o mũdo he luguar de culpa e de trespasamẽto dos mãdados de Deus e loguar de esterro e de peregrinaçó e de door e de choro e de trabalho e de fadigamento e de cansaço e de espanto e de côfusom e de escorregamento e de tresmudamẽto e de passamẽto e de corrupçô e de toruaçom e de força e de prema e de ẽgano ${ }^{24}$. (pp. 119, 2-9)

Sem os anular completamente, o autor do Orto do Esposo restringe severamente os louvores prodigalizados na sua fonte à Criação divina. Não que não partilhe a mesma admiração, como prova o livro II. Não se tratando, porém, de uma exposição de filosofia natural, mas de um tratado de edificação doutrinária e, sobretudo, moral, são o homem e a salvação da alma humana que interessam o monge cisterciense. Daí a prevalência da referência histórica sobre a referência cosmológica e o sentido pejorativo atribuído ao mundo, confundido numa mesma área semântica com termos conotados muito negativamente: carne, diabo, pecado, morte ${ }^{25}$.

Surge de novo a interrogação: uma vez que a opacidade que o mundo adquiriu para a alma maculada pelo pecado fez dele uma realidade perigosa, «sōoobra» ou «jmagem» na qual ela deixou de reconhecer as «uirtudes», o que permite o recurso aos elementos e aos fenómenos do mundo natural como meio de edificação? O Orto do Esposo é a este respeito muito claro. Do mesmo modo que o pecado original obscurece a imagem e semelhança de Deus no ser humano, a Encarnação, o Verbo feito carne, redime-a: Deus, feito à imagem e semelhança do homem, corpo espiritual sem mácula de pecado, redime a matéria e torna de novo acessível a sabedoria de que Adão e os seus descendentes foram privados por sua culpa, ao desobedecerem à ordem de Deus. Com esta proclamação se inicia o livro IV:

Jhesu Christo, que he sabedoria e uerbo de Deus Padre, perdurauel cô elle per todo e en todo, nó podia seer conhecido da creatura do mũdo, que he o homẽ, ataa que sayu da boca do muy alto Senhor Deus e que foy reuelado e demostrado per Deus ante os olhos das creaturas razoauees, que som os homẽẽs (...). (pp. 81, 4-9)

apostada cõ gloria e cõ fremusura da parte decima, ca hũa perfeyçõ de claridade e de uirtude, que he ẽnas partes decima sempre sse esparge côtinuadamẽte sobre as partes mais baixas do mũdo pera as fazer fremosas e apostadas e perfectas» (pp. 118, 20-26).

${ }^{24}$ Cito, mais uma vez, o De proprietatibus rerum segundo a tradução do Orto do Esposo.

25 Cf. P. Daubercies, «Monde», in Catholicisme..., col. 548-549. 
Num outro passo, um pouco adiante, diz ainda o monge alcobacense:

Beendo o Senhor Deus, Padre das misericordias e Deus de toda côsalaçô, como o homẽ era cego e dessenparado de toda graça, reuellou e demostrou-lhe o seu uerbo proprio segredo $^{26}$, que he o seu Filho, que he fonte de sabedoria deuinal (...). (pp.87, 6-9)

É assim pela carne - carne de Cristo, Deus feito à imagem e semelhança da criatura, que por seu intermédio lhe desvela os seus segredos inscritos no mundo composto, como o homem/como Cristo dos elementos - que de novo o ser humano ascenderá ao espiritual e à visão do Paraíso. Por ela, o homem readquire o poder sobre o mundo natural que tinha no tempo original, quando foi chamado a dar nome aos animais. Não se pode deixar de aproximar (mais uma vez, recordemos o livro II) a abertura ao verdadeiro conhecimento do mundo da hermenêutica do livro das Santas Escrituras, que Cristo veio também abrir ${ }^{27}$.

Não sendo original, o autor do Orto do Esposo desenvolve com consistência os fundamentos teológicos em que assenta a sua doutrina do desprezo do mundo, a qual não pode ser reduzida a um conjunto de preceitos ascéticos. É neste contexto que devemos compreender a utilização feita do De proprietatibus rerum. Se é verdade que o discurso monástico de edificação, bem como a própria pregação, desde há muito recorre a exemplos do mundo animal interpretados alegoricamente, eles constituem, pelo número e amplitude que aí têm, um traço particular deste tratado edificante, indissociável da sua antropologia cristã. Revelam, para além disso, que, se o corpus de leituras a que o autor alcobacense teve acesso directamente não ultrapassa em geral as referências habituais da cultura monástica, algumas inovaçôes vão sendo apesar de tudo introduzidas, alargando os seus horizontes ao universo da ciência medieval.

${ }^{26} \mathrm{O}$ passo citado na nota anterior fundamenta, no plano semântico, a correcção introduzida por B. Maler em relação ao manuscrito que lhe serve de base $(A)$, de «segundo» para «segredo» (ms. B).

27 A finalizar o livro III, a partir da interpretação do leão, longamente descrito com base em Bartolomeu Ânglico, como figura de Cristo: «E este leõ Jhesu Christo vẽceo pera abrir o liuro, conprindo a desposiçom de Deus de saluar a geeraçô humanal, e pera vẽcer a mort [e] e pera declarar os segredos da Sancta Scriptura» (pp. 80, 26-29). 